\section{The DRL deficit of rats with septal lesions: Effects of extended training in a mediated environment}

\section{DAVID HOTHERSALL, DONALD ALEXANDER, and ROBERT SLONAKER} The Ohio State University, Columbus, Ohio 43212

Normal rats and rats with septal lesions were given extended training on a DRL 20-sec schedule in either a conventional operant chamber or one containing wooden blocks that the rats chewed. At the end of training, the two normal groups and the septal rats trained with the wooden blocks did not differ in DRL efficiency. This result shows that the DRL deficit found in septal rats can be overcome by training them in environments that facilitate the development of collateral mediating behaviors. The septal rats trained in conventional chambers showed no improvement throughout training.

Rats with lesions of the septum show performance deficits when working on differential reinforcement of low rate responding (DRL) schedules in which they have to respond slowly for food or water reinforcement (Ellen, Wilson, \& Powell, 1964; Burkett \& Bunnell, 1966; Carey, 1967; MacDougall, Van Hoesen, \& Mitchell, 1969; Ellen \& Aitken, 1971). In a recent experiment, we gave groups of normal rats and rats with septal lesions DRL training in one of two different environments: conventional operant chambers or chambers that contained wooden blocks (Slonaker \& Hothersall, 1972). Since the rats chewed and gnawed on the blocks, we were able to investigate the effects of these collateral behaviors upon the efficiency of DRL responding. At the end of $35 \mathrm{~h}$ of DRL training, the DRL behavior of the normal rats trained with the wooden blocks was most efficient, while that of the group of rats with septal lesions trained in conventional chambers was least efficient. In addition, at the end of training, the DRL behavior of the rats with septal lesions trained with the wooden blocks and that of the normal rats trained in conventional chambers was not significantly different. The results of this experiment showed that the DRL deficit of rats with septal lesions can be modified by training them in a "mediation" environment that facilitates the development of collateral behaviors.

In our earlier experiment, the DRL performance of the two groups trained in the mediation environment was continuing to improve at the end of $35 \mathrm{~h}$ of training. In the present experiment, we increased the duration of training to $60 \mathrm{~h}$ in order to assess: the effects of extended training in either a mediation or a nonmediation environment upon the efficiency of
DRL responding in normal rats and in rats with septal lesions.

Subjects

Nineteen male Long-Evans hooded rats were used. The rats were approximately 100 days old at the

Four conventional operant chambers housed in sound-attenuating

enclosures were used. Two of them were slightly modified by each having two $3 \times 2 \times 2$ in. soft pine blocks, suitable for gnawing, bolted to the chamber wall opposite the lever so that they rested on the grid floor. Experimental events were programmed and recorded by electromechanical equipment located in an adjoining room.

\section{PROCEDURE}

Fifteen days prior to the beginning of training, the rats were assigned randomly to either the septal or the normal group. Electrolytic lesions of the septum were produced stereotaxically. Following surgery, the rats were given a 10 -day recovery period on ad lib food and water. They were then placed on a $22-\mathrm{h}$ food deprivation schedule, and 3 days later were shaped to leverpress for a $45-\mathrm{mg}$ food pellet. The following DRL training procedure was then instituted: 10 reinforcements were given on $\mathrm{DRL}$ $10 \mathrm{sec}, 10$ reinforcements on DRL $15 \mathrm{sec}$, followed by $30 \mathrm{~min}$ of training on DRL 20 sec. On all subsequent days, the rats were run for $1 \mathrm{~h}$ with throughout the session. Water was freely available to the rats in their home cages throughout the experiment.

Half of the rats in each of the two groups were assigned to either the "mediation" or the "nonmediation" experimental conditions. The mediation rats were trained in the beginning of the experiment. the DRL 20-sec schedule in effect operant chambers containing the wooden blocks; the nonmediation rats were trained without the wooden blocks. The numbers of responses and reinforcements were recorded daily for each rat. The amount of woodchips recovered from the tray below the chamber floor was weighed and recorded after each session. All of the rats received $60 \mathrm{~h}$ of training on the DRL 20-sec schedule. Any animal in either of the mediation groups that did not consistently chew the wooden blocks during the first $10 \mathrm{~h}$ of training was not used in this experiment. Two of the normal rats and one of the rats with septal lesions did not chew the wood and so were not used. Four groups of four rats each were finally trained.

Once training had been completed, the rats with septal lesions were sacrificed and a histological analysis of their brains was performed.

\section{RESULTS}

Efficiency ratios-reinforcements/ responses (Brady \& Conrad, 1960 )-were computed daily for each rat in all four groups. The individual efficiency ratios were then combined to yield group mean efficiency ratios. Figure 1 shows these efficiency ratios for 125 -h blocks of DRL training for the four experimental groups. The mean daily efficiency ratios and the average amounts of wood chewed during the $60 \mathrm{~h}$ of DRL training were found to be positively correlated. The Spearman rank-difference correlation coefficients (McNemar, 1955) were rho $=.50$ for the normal-mediation group and rho $=.87$ for the septal-mediation group. The total amounts of wood chewed during the last $5 \mathrm{~h}$ of DRL training were $19.4 \mathrm{~g}$ for the normal-mediation group and $27.5 \mathrm{~g}$ for the septal-mediation group. The rats with septal lesions consistently chewed more wood than did the normal rats.

A three-factor analysis of variance (Preparation by Treatment by Days, with repeated measures on days) was performed on the group mean efficiency ratios for the 12 5-day blocks of training (Winer, 1962). The DRL behavior of the normal rats was found to be significantly superior to that of the rats with septal lesions $(F=$ 20.35, df $=1 / 12, p<.01)$. This analysis further showed that the groups trained with the wooden blocks, i.e., the mediation groups, performed more efficiently than did the groups without the wooden blocks, i.e., the nonmediation groups $(\mathrm{F}=42.09, \mathrm{df}=1 / 12, \mathrm{p}<.01)$. The change in DRL performance over the $60 \mathrm{~h}$ of training was also statistically significant $(F=27.32, \mathrm{df}=11 / 132$, $\mathrm{p}<.01)$. Inspection of Fig. 1 shows that the group of rats with septal 


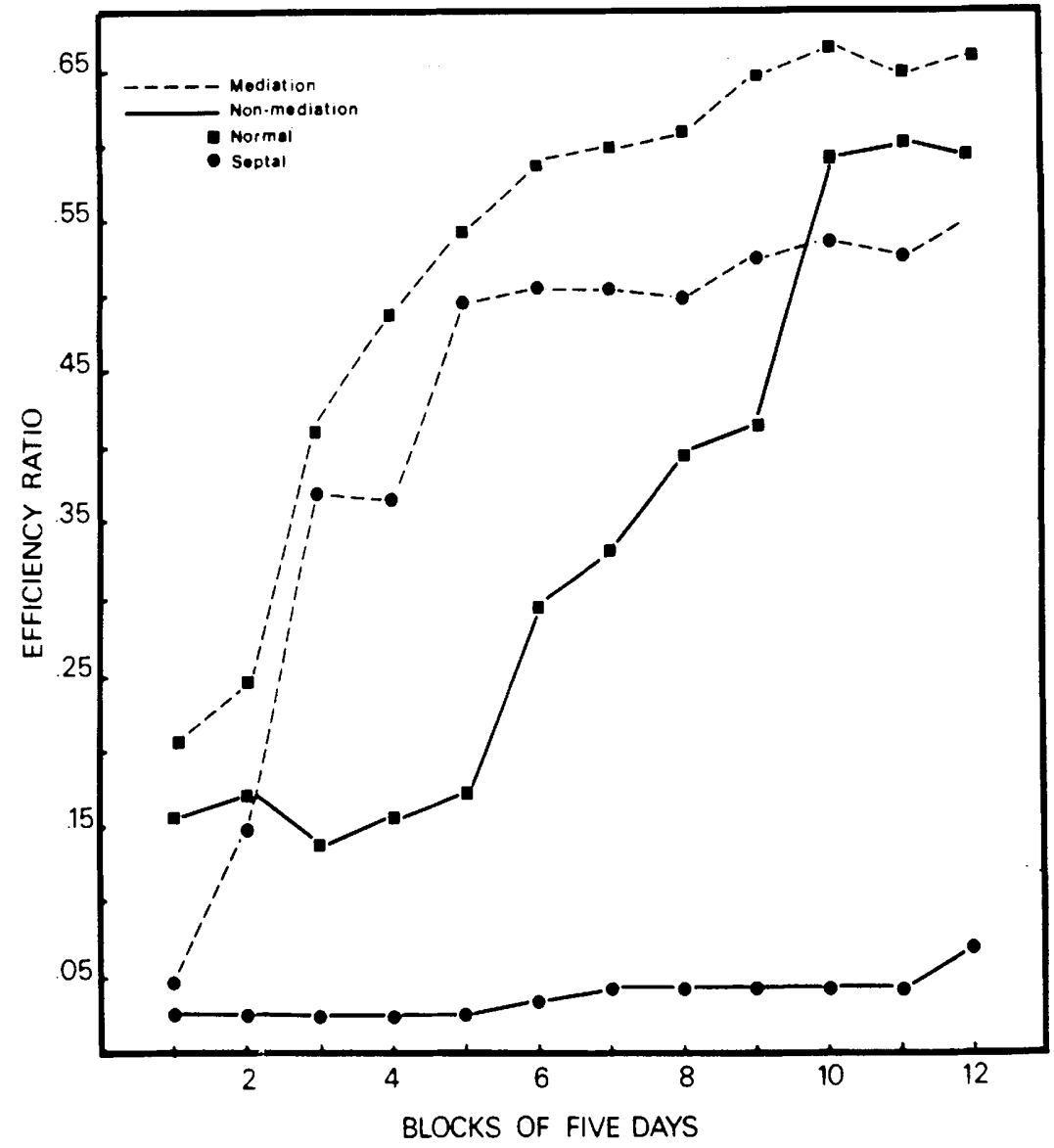

Fig. 1. Group mean efficiency ratios for each block of 5 days of DRL training.

lesions trained in the conventional operant chambers was the one group that did not show an increased DRL efficiency during training. Statistically significant interactions were found for both Treatment by Days $(\mathrm{F}=3.88$, df $=11 / 132, \mathrm{p}<.01)$ and Preparation by Days $(F=5.55$, df $=11 / 132, p<.01)$. Other interactions were nonsignificant.

Comparisons of the performance of the four experimental groups were made, using Scheffé's multiple comparison technique (Winer, 1962). The differences between the terminal behaviors of the normal-mediation, normal-nonmediation, and septal-mediation groups were nonsignificant. The terminal behavior of the septal-nonmediation group was significantly different from that of any of the other three groups.

The histological analysis showed that all eight of the rats in the two septal groups had extensive bilateral damage to the septum. The lesions were similar to those described in detail in our earlier papers (Hothersall, Johnson, \& Collen, 1970; Slonaker \& Hothersall, 1972).

\section{DISCUSSION}

A comparison of the results for the two groups of normal rats used in this reinforcement schedules are in effect. septal lesions trained in the conventional chambers showed no improvement during the $60 \mathrm{~h}$ of DRL training. Similar DRL deficits for rats with septal lesions have been reported by a number of previous investigators, including Ellen \& Aitken (1971). The results of the present experiment show that extended training alone does not overcome the DRL deficit that results from a septal lesion. lesions trained in the mediation behavior. From the third to the seventh $5 \cdot h$ block of training, the performance of this group was significantly superior to that of the group of normal rats trained in conventional chambers. Placing the wooden blocks in the operant chambers appears to have facilitated the development of a particular type of collateral behavior, i.e., wood-chewing. In the normal rats trained in conventional chambers, collateral behaviors occurring during the DRL interval had to develop spontaneously. Consequently, the DRL behavior of these animals was initially less efficient. At the end of $60 \mathrm{~h}$ of DRL training, the DRL behavior of the rats with septal lesions trained in the mediation environment was not significantly different from that of either of the two groups of normal rats but was clearly superior to that of the rats with septal lesions trained in conventional chambers.

The results of this experiment confirm and extend the earlier results we have reported (Slonaker \& Hothersall, 1972). They show that the DRL deficit of rats with septal lesions can be overcome by training the rats in an environment that facilitates the development of collateral mediating $\checkmark$ behaviors.

\section{REFERENCES}

BRADY, J. V., \& CONRAD, D. G. Some effects of brain stimulation on timing behavior. Journal of the Experimental A nalysis of Behavior, 1960, 3, 93-106.

experiment shows that the DRL behavior of the group trained in the mediation environment was more efficient. This result confirms earlier reports of superior DRL performance in normal rats trained in environments that facilitate the development of collateral mediating behaviors (Laties, Weiss, \& Weiss, 1969). In a recent paper, Staddon \& Simmelhag (1971) gave a number of examples of such mediating (collateral, adjunctive, interim) behaviors, and stressed their importance when time-related

The DRL behavior of the rats with

During training, the rats with septal environment showed a systematic increase in the efficiency of their DRL
BURKETT, E. E., \& BUNNELL, B. N Septal lesions and the retention of DRL performance in the rat. Journal of Comparative \& Physiological Psychology, 1969, 67, 344-351.

CAREY, $\dot{R}$. J. Contrasting effects of increased thirst and septal ablations on DRL responding in rats. Physiology \& Behavior, 1967, 2, 287-290.

ELLEN, P., WILSON, A. S., \& POWELL, E. W. Septal inhibition and timing behavior in the rat. Experimental Neurology. $1964,10,120-132$.

ELLEN, P., \& AITKEN, W. C. Absence of temporal discrimination following septal lesions. Psychonomic Science, 1971,22, 129-131.

HOTHERSALL, D., JOHNSON, D. A., \& COLLEN, A. Fixed-ratio responding following septal lesions in the rat Journal of Comparative \& Physiological Psychology, 1970, 73, 470-476.

LATIES, V. G., WEISS, B., \& WEISS, A. B. Further observations of overt 'mediating behavior and the discrimination of time. Journal of the Experimental Analysis of Behavior, $1969,12,43-57$. W.. \& MITCHELL, J. C. Anatomical organization of septal projections and maintenance of DRL behavior in rats. Journal of Comparative \& Physiological Psychology, 1969,68, 568-575.

McNEMAR, Q. Psychological statistics. New York: Wiley, 1955.

SLONAKER, R. L.. \& HOTHERSALL, D Collateral behaviors and the DRL deficit of rats with septal lesions. Journal of Comparative \& Physiological Psychology.
MacDOUGALL, J. M., Van HOESEN, G. 
1972, 80, 91-96.

STADDON, J. E. R., \& SIMMELHAG, V. L.

The "superstition" experiment: A reexamination of its implications and

principles of adaptive behavior.

Psychological Review, 1971, 78, 3-43.
WINER, B. J. Statistical principles in experimental design. New York: MeGraw-Hill, 1962. 